\title{
Controlled oxygen therapy and pulmonary heart failure
}

\author{
A. C. UDE and P. HOW A R D ${ }^{1}$ \\ Department of Medicine, University of Sheffield, The Royal Hospital, West Street, Sheffield S1 3SR
}

\begin{abstract}
One hundred and sixty-six episodes of pulmonary heart failure were treated in 40 patients with chronic bronchitis. The natural history of the disease is described when controlled oxygen is the principal therapy. Only eight episodes of heart failure required intermittent positive pressure ventilation. Despite careful attention to the details of the controlled oxygen technique the longterm survival of these patients was no better than during an earlier period when oxygen was either not given or administered intermittently for short periods. The implications of this finding are discussed.
\end{abstract}

It is believed that the treatment of pulmonary heart failure secondary to bronchitis with obstruction in the airways depends upon the relief of severe hypoxia. Unlimited oxygen leads to depression of ventilation and so-called 'carbon-dioxide narcosis' (Donald, 1949; Sieker and Hickam, 1956). Barach (1938) suggested that oxygen could be given at modest concentrations which would allow the relief of severe hypoxia and yet avoid a rapid increase of arterial carbon dioxide. Donald (1953) and Campbell (1960) developed the technique of controlled oxygen therapy whereby the inspired oxygen concentration is maintained around $30 \%$. Confusion and drowsiness can still be a problem even at these oxygen concentrations. Other workers thus prefer intermittent positive pressure respiration (IPPR) as a means of ensuring relief of hypoxia and removal of carbon dioxide. It is the purpose of this paper to review our experience with controlled oxygen therapy in 40 patients, to describe the natural history of pulmonary heart failure when controlled oxygen is the principal therapy, and to confirm that positive pressure respiration is largely unnecessary.

\section{METHODS}

All patients had chronic bronchitis with airways obstruction and attended a bronchitis outpatient clinic. Chronic bronchitis was defined as a productive cough on most days for at least three months of the year for two or more years. The sputum was either continuously or intermittently purulent. Chest illnesses or exacerbations of bronchitis occurred at least once per

${ }^{1}$ Requests for reprints to P. H. year. The forced expiratory volume $\left(\mathrm{FEV}_{0.75}\right)$ was $\stackrel{\mathbb{S}}{=}$ less than 1 litre and the FEV \% FVC below 60 in al $\overrightarrow{0}$ patients. Pulmonary heart failure (cor pulmonale) wasthe reason for admission to hospital. The tongue was invariably cyanosed. Heart failure was diagnosed bp the presence of a raised jugular venous pressure, right ventricular heave in the substernum, enlarged tendeo liver, and peripheral oedema. All patients were re\% quired to have cyanosis, raised jugular venous pres 8 sure, and a right ventricular heave for admission to the study. The oedema was graded in the first attacle as absent, slight (ankles only), moderate (ankles and legs) and severe (legs and ascites). The electrocardio gram was read in the first attack of heart failure? note being taken of $P$ pulmonale ( $P$ wave $>2 \mathrm{~mm}$ i S2), and right ventricular hypertrophy and straip (dominant $R$ and inverted $T$ in $V 1$ to 3 , dominant $R_{x}^{0}$ in aVR, and dominant $S$ in V5). By descriptive classie fication these patients could be placed in the 'blue 3 . bloater', BB or BE divisions of Fletcher, Hugh-Jones McNichol, and Pride (1963).

All patients admitted to hospital from 1967 to the end of 1969 were included if they satisfied the above criteria. Patients in terminal respiratory and cardia? failure believed to be secondary to predominante. clinical emphysema were excluded as far as possiblen. These patients had been seen previously in the out patient clinic and were known to have clinical manis festations of severe emphysema without obviou cyanosis of the tongue or episodes of congestive heart failure. During the two-year interval many patients were treated who had survived repeated bouts of faile ure during an earlier period. These were included i the study.

Oxygen was administered by an oxygen tent (Mark 4, Oxygenaire Ltd.) or by nasal catheters (British Oxy gen Ltd.). An arterial blood sample was withdraw into heparinized glass syringes from the brachia $\vec{B}$ artery soon after admission and analysed immediately 
for $\mathrm{pH}$, oxygen tension, and carbon dioxide with Astrup or E.I.L. electrodes. Severe heart failure (jugular venous pressure raised $>5-6 \mathrm{~cm}$ ), drowsiness, and confusion were indications for tent therapy. Oxygen was delivered to the tent initially at flow rates between 4 and 6 litres per minute when samples of tent gas taken by long catheters from the top of the tent recorded oxygen concentrations between 25 and $30 \%$. Patients with less severe failure who were lucid started on nasal catheters at oxygen flow rates between 1 and 2 litres per minute. $A$ number of the longest survivors, who were first treated more than five years ago, did not have continuous oxygen therapy but this has not been the practice of the department in more recent years. The clinical state was observed carefully after commencement of oxygen, particularly the level of consciousness. Increasing confusion or drowsiness was treated first of all with intramuscular amphetamine sulphate, $10 \mathrm{mg}$ sixhourly. If confusion or drowsiness persisted, or if the arterial $\mathrm{PCO}_{2}$ had climbed rapidly to values over 70 $\mathrm{mmHg}$ the oxygen flow was reduced. The amphetamine was continued for the duration of oxygen treatment. Most tent patients and about half of those on nasal catheters had amphetamine. Thus in the first stage of treatment the oxygen concentration in the inspired air was often as low as $23-24 \%$ but after two or three days it was usually possible to increase the oxygen concentration steadily to reach around $30 \%$ after a further 7-10 days.

Arterial blood gas estimations were repeated within 24 hours according to the clinical state and thereafter at increasing intervals to recovery from heart failure as shown by the disappearance of oedema and return of the jugular venous pressure to normal. If, despite this careful 'titration' of the oxygen therapy to the clinical state and the arterial blood gases, no improvement or a fall in arterial oxygen tension $\left(\mathrm{PaO}_{2}\right)$ to below $40 \mathrm{mmHg}$ occurred within 24 hours then therapy was abandoned and IPPR begun.

Figure 1 shows an example of the effect on $\mathrm{PaO}_{2}$ and arterial carbon dioxide tension $\left(\mathrm{PaCO}_{2}\right)$ of giving increasing concentrations of oxygen with nasal catheters. The first arterial blood gases were taken during air breathing. Oxygen was started at a flow of $1 \mathrm{l} . / \mathrm{min}$. $\mathrm{PaCO}_{2}$ rose sharply in the first few hours of therapy and the oxygen flow was reduced to 0.751 .1 min. The rise of $\mathrm{PaCO}_{2}$ was slowed but the $\mathrm{PaO}_{2}$ fell to $39-40 \mathrm{mmHg}$. At the end of the second day the oxygen flow was increased to $1.251 . / \mathrm{min}$. $\mathrm{PaO}_{2}$ rose steadily to $62 \mathrm{mmHg}$ as did $\mathrm{PaCO}_{2}$ to a peak value of $77 \mathrm{mmHg}$. Thereafter $\mathrm{PaCO}_{2}$ steadily declined. After 32 days the oxygen therapy was stopped for a few hours. PaOz fell sharply to $48 \mathrm{mmHg}$ and had failed to reach its former levels some hours after oxygen was restarted (when the blood sample was taken). In this patient the heart failure was clinically relieved but the improvement of blood gases could not be sustained without oxygen enrichment of the inspired air.

Controlled oxygen therapy was continued for at least one week but in most patients for two to three weeks. Tent treatments were often followed for some

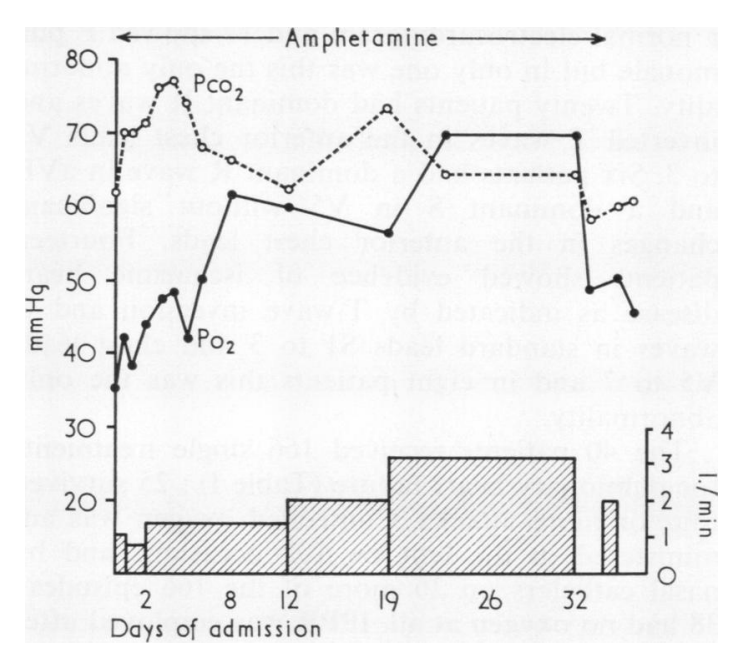

FIG. 1. Arterial blood gas changes during nasal oxygen therapy given for an acute exacerbation of pulmonary heart failure. Oxygen flow rate.

days with oxygen via nasal catheters. Oxygen therapy was withdrawn slowly during one further week when signs of cardiac failure had subsided, first during the day and later at night.

Although oxygen therapy was considered most important all patients received a diuretic (mersalyl on alternate days, or daily chlorthiazide, or daily frusemide), potassium supplements, and an antibiotic (penicillin and streptomycin, or ampicillin, or oxytetracycline). Antispasmodics such as aminophylline compounds, isoprenaline, and orciprenaline were occasionally given. Digoxin was not used.

A number of patients were treated in other hospitals for some exacerbations. Although blood gases were usually not available these episodes have been included in our analysis.

\section{RESULTS}

Forty patients were studied ( 36 male and 4 female). The mean age in the first attack of heart failure was $56 \cdot 3$ (S.D. $\pm 7 \cdot 8$ ) years. The length of history of chronic bronchitis was at least five years and often more than 10 years in all but two patients. In the latter, the history appeared to be only one to two years. The severity of the heart failure, judged clinically, varied from mild to severe. In the first attack, nine had no oedema but other evidence of congestive failure and seven had mild oedema; in 16 oedema was moderate and in eight severe. These figures were probably influenced by oral diuretic therapy given by the family doctor in a few patients. Five patients had 
a normal electrocardiogram and 17 showed $P$ pulmonale but in only one was this the only abnormality. Twenty patients had dominant $R$ waves and inverted $T$ waves in the anterior chest leads V1 to 3. Six patients had a dominant $R$ wave in aVR and a dominant $S$ in V5 without significant changes in the anterior chest leads. Fourteen patients showed evidence of ischaemic heart disease as indicated by $T$-wave inversion and $Q$ waves in standard leads $S 1$ to 3 and chest leads V5 to 7 and in eight patients this was the only abnormality.

The 40 patients received 166 single treatments for pulmonary heart failure (Table I) ; 25 survived four or more attacks. Controlled oxygen was administered in the tent on 102 occasions and by nasal catheters on 26 more of the 166 episodes; 38 had no oxygen at all. IPPR was employed after failure of tent therapy in eight instances. Thirtyone patients have died at the time of preparation of this report ; four patients perished during or shortly after the first attack. The mean survival for the whole group since the onset of heart failure was 42.9 (S.D. \pm 34.9 ) months and for the 31 who have died 30.8 (S.D. \pm 36.4 ) months. Twenty-eight patients died in an exacerbation of heart failure, two with cerebral haemorrhage and one with a cardiac infarction. Most died at home and the family doctor was asked about the death. One of the 28 men was also known to have a carcinoma of the lung.

T A B L E I

DISTRIBUTION OF EPISODES OF HEART FAILURE AMONG THE 40 PATIENTS

\begin{tabular}{c|c}
\hline $\begin{array}{c}\text { Episodes of Heart } \\
\text { Failure }\end{array}$ & $\begin{array}{c}\text { No. of } \\
\text { Patients }\end{array}$ \\
\hline $1-3$ & 15 \\
$4-6$ & 17 \\
$7-9$ & 7 \\
10 & 1 \\
\hline Total & 40 \\
\hline
\end{tabular}

Figure 2 shows the time interval between successive treatments of heart failure. Measurements are not included beyond the seventh exacerbation as numbers were too small for statistical analysis. Despite wide variation the trend of diminishing duration of remission is clear. For some patients, the heart failure was not completely relieved in the final stages. The mean presenting arterial oxygen tension in the first attack was 52.2 (S.D. \pm 11.0 ) mmHg. Figures 3, 4, and 5 show changes in $\mathrm{PaO}_{2}$, $\mathrm{PaCO}_{2}$, and arterial oxygen saturation $\left(\mathrm{SaO}_{2}\right)$. The

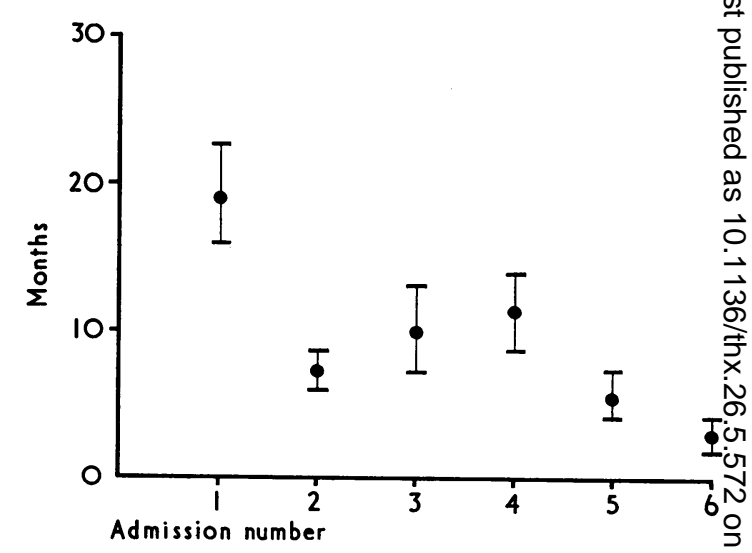

FIG. 2. Time interval between successive episodes of heart $\vec{t}$ failure for the whole group of 40 patients. Mean values withD one standard error are given.

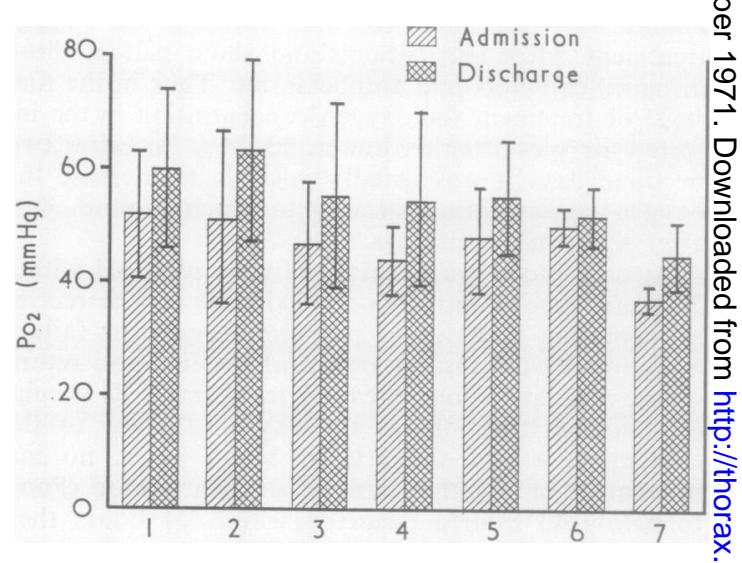

FIG. 3. Mean oxygen tension in arterial blood during successive episodes of heart failure. One standard deviation. of the mean is given.

first blood gas estimation taken within two days of admission and the final one shortly before dis- $\frac{D}{0}$ charge on each occasion were used for analysis. The patients were breathing air at the time of $\mathcal{N}$ sampling. The mean and standard deviation of all $N$ measurements up to the seventh exacerbation are N shown. $\mathrm{PaO}_{2}$ and $\mathrm{SaO}_{2}$ improved during each treat- $\mathrm{\omega}$ ment but the admission values fell progressively. Mean $\mathrm{PaCO}_{2}$ was little changed throughout the $\stackrel{0}{=}$ study but in individual patients there was great $\stackrel{\Phi}{\mathscr{S}}$ variability in the outcome of treatment. Thus $\mathrm{PaCO}_{2}$ was either unchanged, increased or decreased after single episodes of failure. There was $\stackrel{0}{\mathbb{D}}$ a trend towards more exacerbations and a longer $\frac{O}{\mathbb{D}}$ survival the higher the initial $\mathrm{PaO}_{2}$ in the first $\stackrel{2}{9}$ 


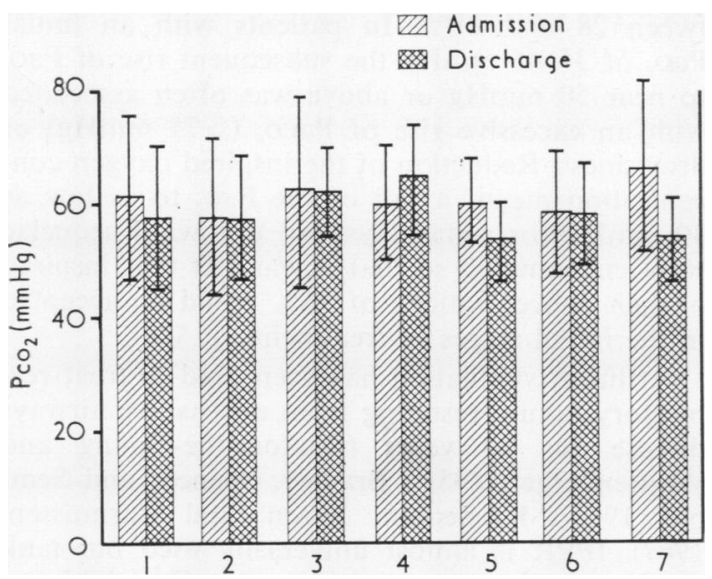

FIG. 4. Mean arterial carbon dioxide tension during successive episodes of heart failure. One standard deviation of the mean is given.

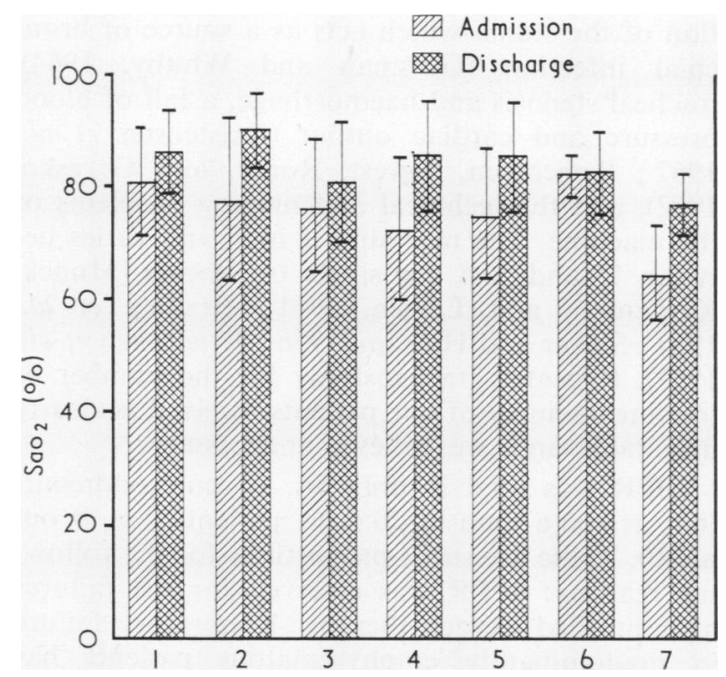

FIG. 5. Mean arterial saturation for oxygen during successive episodes of heart failure. One standard deviation of the mean is given.

attack, although the changes were not statistically significant. Figure 6 shows two individual plots as examples of the blood gas changes during successive treatments of heart failure. The trend of progressively falling $\mathrm{PaO}_{2}$ but variable $\mathrm{PaCO}_{2}$ is evident.

Eight patients were treated with IPPR after tent therapy failed; two had influenzal bronchopneumonia and both died shortly after IPPR was

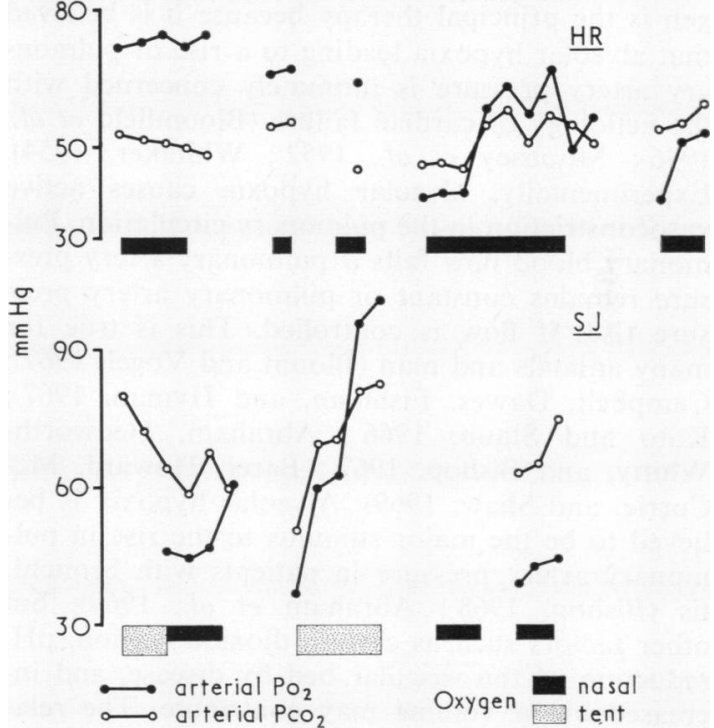

FIG. 6. Arterial blood gases during successive episodes of heart failure in two patients. Patient HR had five treatments and patient $S J$, four.

begun; three had lobar pneumonia and all made a reasonable recovery, so much so in one patient that light work has been possible for over a year. The remaining three were probably in the terminal phases of disease ; one died on the ventilator and two recovered to die at home shortly after discharge.

The major complication of controlled oxygen is mental change. All patients with pulmonary heart failure treated with oxygen are liable to confusion, delirium, delusions, hallucinations, and coma. The symptoms are often present before therapy but are worse with treatment. All our patients were affected but in most no more than mild confusion was encountered. Small doses of chlorpromazine ( $25 \mathrm{mg}$ two or three times daily) were given for restlessness and delusions in about 20 instances. In no case was the problem so troublesome that treatment had to be abandoned. The symptoms were most severe in those showing steep rises of $\mathrm{PaCO}_{2}$ but improvement occurred when the inspired oxygen was reduced.

\section{DISCUSSION}

Controlled oxygen therapy gives continuous oxygen to patients with pulmonary heart failure without producing carbon dioxide narcosis and it is hoped that it avoids the need for IPPR. Oxy- 
gen is the principal therapy because it is believed that alveolar hypoxia leading to a rise of pulmonary artery pressure is intimately concerned with the aetiology of cardiac failure (Bloomfield et al., 1946 ; Mounsey et al., 1952; Whitaker, 1954). Experimentally, alveolar hypoxia causes active vasoconstriction in the pulmonary circulation. Pulmonary blood flow falls if pulmonary artery pressure remains constant or pulmonary artery pressure rises if flow is controlled. This is true for many animals and man (Blount and Vogel, 1967 ; Campbell, Dawes, Fishman, and Hyman, 1967 ; Kato and Staub, 1966 ; Abraham, HedworthWhitty, and Bishop, 1967 ; Barer, Howard, McCurrie, and Shaw, 1969). Alveolar hypoxia is believed to be the major stimulus to the rise in pulmonary artery pressure in patients with bronchitis (Bishop, 1968; Abraham et al., 1969), but other factors such as carbon dioxide tension, $\mathrm{pH}$, reduction of the vascular bed by disease, and increased blood volume may contribute. The relative importance of these factors compared with hypoxia is still disputed. Pulmonary heart failure is assumed to result from the rise in pulmonary artery pressure, but the issue is complicated by the effects of chronic hypoxia directly on cardiac muscle. Experimentally it causes the size of both the right and left ventricular muscle to increase (Cook, Barer, Shaw, and Clegg, 1970), suggesting a direct effect on muscle not related to the pulmonary vascular consequences. Cardiac muscle changes might contribute to cardiac failure.

The natural history of pulmonary heart failure portrayed in this study supports alveolar hypoxia as the most important causative factor. Thus, as heart failure subsided, hypoxia lessened and less satisfactory recoveries were obtained in the longer term as $\mathrm{PaO}_{2}$ steadily declined. Patients with a lower presenting $\mathrm{PaO}_{2}$ at the first visit tended to survive for shorter periods. Arterial carbon dioxide tension, on the other hand, did not seem to be important as the changes varied, being sometimes greater after recovery than in the acute phase. Hydrogen ion concentration was unlikely to be a major factor as $\mathrm{pH}$ seldom fell below 7.30.

Controlled oxygen therapy is used to maintain $\mathrm{PaO}_{2}$ sufficiently high to ensure adequate function of vital organs such as the brain. Hutchison, Flenley, and Donald (1964) considered an arterial oxygen tension of $50 \mathrm{mmHg}$ as safe but Campbell (1964) suggested that $40 \mathrm{mmHg}$ was unlikely to lead to untoward effects. Eldridge (1966), from pyruvate/lactate studies, supported the lower figures. During treatment of our patients, the inspired oxygen was initially controlled be- tween 28 and $31 \%$. In patients with an initio $\mathrm{PaO}_{2}$ of $35-45 \mathrm{mmHg}$ the subsequent rise of $\mathrm{Pac}$ to near $50 \mathrm{mmHg}$ or above was often associated with an excessive rise of $\mathrm{PaCO}_{2}(>75 \mathrm{mmHg})$ of drowsiness. Reduction of the inspired oxygen conos centration meant a fall of the $\mathrm{PaO}_{2}$ to as low as $40 \mathrm{mmHg}$ for some days. No untoward sequelaewere encountered so that it was felt that inspired oxygen concentrations of $25 \%$ could be accepted in the initial stages of treatment.

Artificial ventilation has been used to treat reso piratory failure resulting from obstructive airway's disease for 20 years (Boutourline-Young an\& Whittenberger, 1951 ; Bradley, Spencer and Sem ple, 1964 ; Kristensen, Jessen, and Rasmussen? 1967). IPPR is almost universally used but $\tan \overrightarrow{{ }^{\prime}}$ respirators are advocated by some (Grendahl an Refsum, 1965) who wish to avoid tracheostomy The relief of hypoxia and the removal of carbow dioxide are ensured but the complications of the technique are formidable particularly in those with pulmonary heart failure. They include infece tion of the stoma which acts as a source of bronchial infection (Gotsman and Whitby, 1964) tracheal stenosis and haemorrhage, a fall of bloos pressure and cardiac output (Kristensen et al. 1967 ; Roncoroni, Agrest, Roehr, and Grzesko: 1962), and the technical and nursing problems ob the machine. The mortality is high and varies be $\vec{F}$ tween 15 and $50 \%$ for single treatments (Munck고 Kristensen, and Lassen, 1961 ; Bradley et al. 1964 ; Sieker and Hickam, 1956 ; Kristensen et al: 1967). Repeated tracheostomy for the number of treatments many of our patients received is clearly unsuitable and, we believe, unnecessary.

IPPR was used in only $5 \%$ of our treatments (but at some time in $20 \%$ of patients, i.e., 8 our of 40). These are small proportions for the follow ing reasons: IPPR was reserved for the failures of controlled oxygen therapy. Respiratory failure in predominantly emphysematous patients has been excluded as far as possible. The clinica? severity of pulmonary heart failure varies widelyn and this study includes patients with lesser degrees of heart failure who would probably never haves been treated with artificial ventilation even in cen $N$ tres which favour this therapy. Particular care was taken not to precipitate the need for ventilation byo too high a concentration of oxygen in the initia $\bar{D}$ therapy.

It was thus possible to treat $95 \%$ of our acute exacerbations successfully with controlled oxygen? in the acute phase, but it is important to knows whether the long-term progress is improved. $A_{\stackrel{\Omega}{\Omega}}$ progressive fall of $\mathrm{PaO}_{2}$ occurs (Fig. 3), witho 
recovery from successive exacerbations becoming less complete. There may be several reasons for refractoriness to treatment, increasing lung disorder causing greater hypoxia, fixation of structural changes in pulmonary vessels, and perhaps irreversible damage to cardiac muscle.

Table II compares the survival of a group of 108 patients with pulmonary heart failure studied by Stuart-Harris and Hanley in the same department in 1957 with the survival of our 40 patients. There is every reason to believe that the patients were comparable in clinical terms. Their treatment would differ in that the former group received oxygen only intermittently for short periods or not at all and that oral diuretics were not available. There is no major difference in survival. Thus despite all our care with the technique of controlled oxygen the long-term prognosis appears unaffected.

\section{T A B L E I I}

SURVIVAL OF TWO GROUPS OF PATIENTS WITH PULMONARY HEART FAILURE

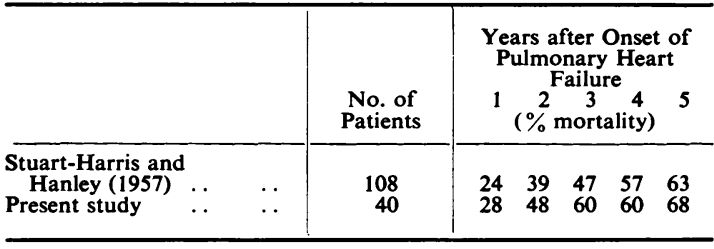

The duration of oxygen therapy in this study was essentially short-term but evidence is accumulating to suggest that an improvement in long-term prognosis might depend upon much longer periods of oxygen administration. Abraham, Cole, and Bishop (1968) gave oxygen continuously at a rate of 1 to 3 litres per minute through nasal catheters for four to eight weeks. The raised pulmonary artery pressure slowly returned towards normal values. They suggested that structural changes due to hypoxia in small pulmonary vessels of patients with bronchitis regressed during therapy but the improvement could be achieved only slowly. Petty and Finigan (1968) gave oxygen for periods between 7 and 41 months to 33 patients with hypoxia and irreversible airways obstruction living at high altitude. The expected mortality after two years was halved.

We think that the majority of patients with cor pulmonale secondary to chronic bronchitis can be treated with controlled oxygen even if it means starting with only small additions of oxygen to the inspired air. The long-term prognosis is not influenced by closer attention to the details of controlled oxygen during the acute phase. Relapse invariably occurs, and it is doubtful whether these short periods of therapy are having any effect on the pathological changes in the pulmonary circulation. Much longer periods of therapy, extending over months, perhaps years, may well be necessary, and this will depend upon an effective domiciliary oxygen service.

This work was supported in part by a generous personal grant to P.H. from the Wellcome Trust. Professor Sir Charles Stuart-Harris, M.D., F.R.C.P., gave much appreciated help and criticism.

\section{REFERENCES}

Abraham, A. S., Cole, R. B., and Bishop, J. M. (1968). Reversal of pulmonary hypertension by prolonged oxygen administration to patients with chronic bronchitis. Circulat. Res., 23, 147.

$-\longrightarrow$, Green, I. D., Hedworth-Whitty, R. B., Clarke, S. W., and Bishop, J. M. (1969). Factors contributing to the reversible pulmonary hypertension of patients with acute respiratory failure studied by serial observations during recovery. Circulat. Res., 24, 51.

- , Hedworth-Whitty, R. B., and Bishop, J. M. (1967). Effects of acute hypoxia and hypervolaemia singly and together, upon the pulmonary circulation in patients with chronic bronchitis. Clin. Sci., 33, 371.

Barach, A. L. (1938). Physiological methods in the diagnosis and treatment of asthma and emphysema. Ann. intern. Med., 12, 454.

Barer, G. R., Howard, P., McCurrie, J. R., and Shaw, J. W. (1969). Changes in the pulmonary circulation after bronchial occlusion in anesthetized dogs and cats. Circulat. Res., 25, 747.

Bishop, J. M. (1968). In Form and Function in the Human Lung, ed. G. Cumming and L. B. Hunt, p. 134. Livingstone, Edinburgh and London.

Bloomfield, R. A., Lauson, H. D., Cournand, A., Breed, E. S., and Richards, D. W., Jr. (1946). Recording of right heart pressures in normal subjects and in patients with chronic pulmonary disease and various types of cardio-circulatory disease. J. clin. Invest., 25, 639.

Blount, S. G., and Vogel, J. H. K. (1967). Altitude and the pulmonary circulation. Advanc. intern. Med., 13, 11.

Boutourline-Young, H. J., and Whittenberger, J. L. (1951). The use of artificial respiration in pulmonary emphysema accompanied by high carbon dioxide levels. J. clin. Invest., 30, 838.

Bradley, R. D., Spencer, G. T., and Semple, S. J. G. (1964). Tracheostomy and artificial ventilation in the treatment of acute exacerbations of chronic lung disease: a study in 29 patients. Lancet, $1,854$.

Campbell, A. G. M., Dawes, G. S., Fishman, A. P., and Hyman, A. I. (1967). Pulmonary vasoconstriction and changes in heart rate during asphyxia in immature foetal lambs. J. Physiol. (Lond.), 192, 93.

Campbell, E. J. M. (1960). A method of controlled oxygen administration which reduces the risk of carbondioxide retention. Lancet, $2,12$.

(1964). Management of respiratory failure. Brit. med. J., 2, 1328.

Cook, C., Barer, G. R., Shaw, J. W., and Clegg, E. J. (1970). Growth of the heart and lungs in normal and hypoxic rodents. J. Anat. (Lond.), 107, 384.

Donald, K. (1949). Neurological effects of oxygen. Lancet, 2, 1056. 
- (1953). Acute respiratory insufficiency. Lancet, 1, 495.

Eldridge, F. (1966). Blood lactate and pyruvate in pulmonary insufficiency. New Engl. J. Med., 274, 878.

Fletcher, C. M., Hugh-Jones, P., McNicol, M. W., and Pride, N. B. (1963). The diagnosis of pulmonary emphysema in the presence of chronic bronchitis. Quart. J. Med., 32, 33.

Gotsman, M. S., and Whitby, J. L. (1964). Respiratory infection following tracheostomy. Thorax, 19, 89.

Grendahl, H., and Refsum, H. E. (1965). Artificial ventilation with tank respirators in the routine treatment of severe pulmonary failure due to chronic pulmonary disease. Acta med. scand., 177, 539.

Hutchison, D. C. S., Flenley, D. C., and Donald, K. W. (1964). Controlled oxygen therapy in respiratory failure. Brit. med. J., 2, 1159.

Kato, M., and Staub, N. C. (1966). Response of small pulmonary arteries to unilobar hypoxia and hypocapnia. Circulat. Res., 19, 426.

Kristensen, H. S., Jessen, O., and Rasmussen, K. (1967). Treatment of severe respiratory insufficiency in diffuse chronic lung disease by tracheostomy and intermittent positive pressure ventilation (IPPV). Postgrad. med. J., 43, 244.
Mounsey, J. P. D., Ritzmann, L. W., Selverstone, N. J., Briscoe, W. A., and McLemore, G. A. (1952). Circulatory changes in severe pulmonary emphysema. Brit. $\stackrel{\overrightarrow{\mathbb{D}}}{\mathrm{Q}}$ Heart J., 14, 153.

Munck, O., Kristensen, H. S., and Lassen, H. C. A. (1961). ڤొ Mechanical ventilation for acute respiratory failure in diffuse chronic lung disease. Lancet, 1, 66.

Petty, T. L., and Finigan, M. M. (1968). Clinical evaluation $\overrightarrow{\vec{\omega}}$ of prolonged ambulatory oxygen therapy in chronic $\mathcal{S}$ airway obstruction. Amer. J. Med., 45, 242.

Roncoroni, A. J., Agrest, A., Roehr, E., and Grzesko, S. (1962). Hemodynamics during mechanical ventilation. O Amer. Heart J., 64, 207.

Sieker, H. O., and Hickam, J. B. (1956). Carbon dioxide $V$ intoxication: the clinical syndrome, its etiology and $N$ management with particular reference to the use of 음 mechanical respirators. Medicine (Baltimore), 35, 389.

Stuart-Harris, C. H., and Hanley, T. (1957). Chronic Bron- $\mathcal{C}$ chitis, Emphysema and Cor Pulmonale, p. 124. John $\frac{\mathbb{D}}{O}$ Wright, Bristol.

Whitaker, W. (1954). Pulmonary hypertension in congestive heart failure complicating chronic lung disease. Quart. J. Med., 23, 57. 